\title{
Alleviating diabetes distress and improving diabetes self-management through health coaching in a primary care setting
}

\author{
Charles C Chima 지 , ${ }^{1,2}$ Brenna Swanson, ${ }^{3}$ Nnabuchi Anikpezie, ${ }^{1}$ Jason L Salemi ${ }^{2,4}$
}

'Department of Population Health Science, The University of Mississippi Medical Center, Jackson, Mississippi, USA ${ }^{2}$ Family and Community Medicine, Baylor College of Medicine, Houston, Texas, USA ${ }^{3}$ Department of Nutrition and Dietetics, University of North Dakota, Grand Forks, North Dakota, USA

${ }^{4}$ College of Public Health, University of South Florida, Tampa, Florida, USA

Correspondence to

Dr Charles C Chima;

cchima@umc.edu

Accepted 1 April 2021

Check for updates

(c) BMJ Publishing Group Limited 2021. No commercial re-use. See rights and permissions. Published by BMJ.

To cite: Chima CC

Swanson B, Anikpezie N,

et al. BMJ Case Rep

2021:14:e241759.

doi:10.1136/bcr-2021 -

241759

\section{SUMMARY}

Considering the rising global burden of diabetes and its complications, effective interventions for addressing barriers to diabetes self-management are needed. Diabetes distress, a psychological barrier to diabetes self-management, has become increasingly recognised in the literature, but effective and feasible ways of addressing it in routine primary care settings are not known. We present the case of a middle-aged nonHispanic white American woman with poorly controlled diabetes (haemoglobin A1c (HbA1c): 13.9\%) and elevated diabetes distress (baseline Diabetes Distress Scale Score: 2.53) who participated in a health coaching intervention. After the 5-month programme, which included eight 45 minute long sessions with a trained health coach, the patient achieved and sustained a 0.8-point reduction in diabetes distress, an improvement in insulin adherence and a 3.6-point reduction in $\mathrm{HbA1c}$. This case demonstrates a novel approach to managing diabetes distress that entails providing patients a safe, nonjudgemental space to express their feelings and explore challenges with diabetes self-management.

\section{BACKGROUND}

Diabetes distress is a form of psychological distress specific to individuals living with diabetes, encompassing the burden, fears and challenges of dealing with the disease and its complications. ${ }^{1}$ It is important to address diabetes distress because it is associated with poor self-management behaviours and poor diabetes control. ${ }^{2-4}$ The 17-item Diabetes Distress Scale (DDS), one of the common scales for measuring diabetes distress, assesses four domains of diabetes distress, namely emotional burden, regimen distress, interpersonal distress and physician-related distress. ${ }^{5}$ These four subscales have been used in previous studies and are considered reliable and valid. ${ }^{2}{ }^{6}$ Evidence suggests that diabetes distress is meaningfully associated with diabetes self-management and diabetes control when an individual's DDS score is greater than or equal to 2.0..$^{3} \mathrm{~A}$ mean item score in the range 2.0-2.9 is considered to indicate a moderate level of distress, while a score of 3.0 or above indicates a high level of distress. ${ }^{3}$ Diabetes distress and its four subdomains, as captured in the DDS, each has a score range of $1-6$.

\section{CASE PRESENTATION Clinical presentation}

The patient was a non-Hispanic white American woman in her late 50s whose highest level of education was less than high school and whose annual household income was less than 50 thousand dollars. She had multiple chronic conditions including obesity, controlled hypertension and hyperlipidaemia, and poorly controlled type 2 diabetes (haemoglobin A1C (HbA1c) of 13.9\%). She has been living with type 2 diabetes since 2005 . The patient had a total DDS score of 2.53 at baseline, indicating a moderate level of diabetes distress. The breakdown of the score into subdomains of the DDS showed that regimen distress (score of 4) and emotional burden (score of 3.2) were the primary forms of diabetes distress experienced by the patient.

The clinic enrolled the patient in an intervention that sought to alleviate diabetes distress through health coaching. The patient's diabetes distress in the context of poorly controlled diabetes indicated the need for the intervention. We present the highlights of a novel approach that uses health coaching techniques to help patients with diabetes distress manage the emotional toll of diabetes and improve their diabetes control.

\section{Treatment}

The participant received eight coaching sessions delivered via telephone over a 5-month period: two times per month for the first threemonths and then monthly for the last two months. Each session lasted for approximately 45 minutes. The health coach was a registered dietitian with additional certifications as a Certified Diabetes Care and Education Specialist and Certified Health and Wellness Coach. Notwithstanding her knowledge as a dietitian, the intervention focused on using her professional coaching skills. The coach was external to the patient's routine primary care team and was contracted by the primary care practice to provide the service.

Prior to the first session, the coach spoke with the patient to explain what coaching was and to come to a consensus regarding how they would proceed. Then they set up a coaching schedule for the eight sessions. Highlights of the patient's coaching journey are summarised in the remaining paragraphs in this section. At the first coaching session, the coach and the patient reviewed the patient's concerns and challenges with diabetes care, 
Table 1 Patient's diabetes distress scores at baseline and 2 months post-intervention

\begin{tabular}{|c|c|c|c|}
\hline DDS subscale & Questions (DDS) $^{5}$ & Preintervention item score ${ }^{*} \dagger$ & Postintervention item score ${ }^{*} \dagger$ \\
\hline \multirow[t]{6}{*}{ Regimen Distress } & Not feeling confident in my day-to-day ability to manage diabetes & 1 & 1 \\
\hline & Feeling that I am not testing my blood sugars frequently enough & 3 & 4 \\
\hline & Feeling that I am often failing with my diabetes routine & 6 & 4 \\
\hline & Feeling that I am not sticking closely enough to a good meal plan & 4 & 1 \\
\hline & Not feeling motivated to keep up my diabetes self-management & 6 & 3 \\
\hline & Regimen Distress Domain Score ${ }^{*}$ & 4 & 2.6 \\
\hline \multirow[t]{6}{*}{ Emotional Burden } & $\begin{array}{l}\text { Feeling that diabetes is taking up too much of my mental and physical } \\
\text { energy every day }\end{array}$ & 2 & 2 \\
\hline & $\begin{array}{l}\text { Feeling angry, scared and/or depressed when I think about living with } \\
\text { diabetes }\end{array}$ & 2 & 1 \\
\hline & $\begin{array}{l}\text { Feeling that I will end up with serious long-term complications, no matter } \\
\text { what I do }\end{array}$ & 6 & 1 \\
\hline & Feeling that diabetes controls my life & 3 & 4 \\
\hline & Feeling overwhelmed by the demands of living with diabetes & 3 & 1 \\
\hline & Emotional Burden Domain Score* & 3.2 & 1.8 \\
\hline \multirow[t]{4}{*}{ Interpersonal Distress } & Feeling that friends or family are not supportive enough of self-care efforts & 1 & 1 \\
\hline & $\begin{array}{l}\text { Feeling that friends or family do not appreciate how difficult living with } \\
\text { diabetes can be }\end{array}$ & 1 & 1 \\
\hline & $\begin{array}{l}\text { Feeling that friends or family do not give me the emotional support that I } \\
\text { would like }\end{array}$ & 1 & 1 \\
\hline & Interpersonal Distress Domain Score* & 1 & 1 \\
\hline \multirow[t]{5}{*}{$\begin{array}{l}\text { Physician-related } \\
\text { Distress }\end{array}$} & $\begin{array}{l}\text { Feeling that my doctor does not know enough about diabetes and diabetes } \\
\text { care }\end{array}$ & 1 & 1 \\
\hline & $\begin{array}{l}\text { Feeling that my doctor does not give me clear enough directions on how to } \\
\text { manage my diabetes }\end{array}$ & 1 & 1 \\
\hline & Feeling that my doctor does not take my concerns seriously enough & 1 & 1 \\
\hline & $\begin{array}{l}\text { Feeling that I do not have a doctor who I can see regularly enough about } \\
\text { my diabetes }\end{array}$ & 1 & 1 \\
\hline & Physician-related Distress Domain Score* & 1 & 1 \\
\hline Overall diabetes distress & Diabetes Distress Scale Score & 2.53 & 1.71 \\
\hline
\end{tabular}

* Range for respective item, domain or total diabetes distress score $=1-6$.

tItem Score Likert Scale options: $1=$ not a problem, $2=$ a slight problem, $3=$ a moderate problem, $4=$ somewhat serious problem, $5=a$ serious problem, $6=a$ very serious problem. DDS, Diabetes Distress Scale.

identified the patient's strengths (eg, what has worked for her in the past with regards to diabetes self-management) and created a health vision statement and associated goals. The patient's baseline DDS report provided information on the specific types of distress the patient was feeling the most, that is, regimen distress and emotional burden (table 1) and the specific things about living with diabetes that were upsetting the patient as informed by the DDS questions with the highest scores (table 1). Notably, the patient indicated that she was often failing with her diabetes routine, particularly, she was not taking insulin as prescribed, she lacked motivation to keep up with the demands of diabetes self-management, and she had resigned to fate with a conviction that she would inevitably end up with serious long-term complications of diabetes no matter what she did. These findings informed the development of the coaching priorities.

It was remarkable to note that the patient reported that although she was adherent with her oral medications for diabetes and other comorbidities, she had stopped taking insulin for about fouryears. Initially, she could not properly articulate why she was not taking insulin prior to coaching. She started with saying she hated needles and insulin. With the guidance of the coach, she was able to identify the root cause of her nonadherence as a severe fear of hypoglycaemia as she was not eating regularly. Up to this point, she had not discussed her fears with the doctor. Thus, she identified insulin self-management as an important short-term coaching target and her immediate action plan was to schedule an appointment with her doctor to discuss the insulin situation. Other short-term plans were to reduce her meal portion sizes and to increase her physical activity levels. Her 3-month goal was to achieve a target $\mathrm{HbA1c}$ value of $9 \%$, a meaningful reduction from her baseline value of $13.9 \%$. She set an initial vision to attain a healthier state in life in which she would feel 'strong, wonderful, peaceful and calm.' At the end of the session, the patient expressed that she felt heard, more confident, and empowered to take on her challenges.

At subsequent coaching sessions, the patient's progress on her goals was reviewed, with a focus on specific issues that she was dealing with or wanted to talk about at any given time. By the second coaching session, the patient had scheduled the doctor's appointment as decided from the first session; the appointment was to occur on the day after the second coaching session. Building on the first session, the patient and coach worked on her fears and inertia for insulin, breaking it down to specific actionable items, then they discussed her feeling of control and level of confidence and made a list of issues that the patient will discuss further with the doctor. The patient's strengths and past successes were also explored, allowing her to derive confidence from those experiences. At the end of the second session, the patient stated that she felt much more confident about taking insulin and felt prepared to talk with the doctor the following day, armed with the list of discussion topics for the visit. 
At the doctor's visit that occurred after the second coaching session, the patient discussed her challenges with insulin as articulated. This triggered a prolonged visit during which the doctor spent more than 30 minutes educating her on proper self-monitoring of blood glucose and the symptoms of hypoglycaemia, to ameliorate her fears of hypoglycaemic coma. She was also educated on the need for better control of her blood glucose and the importance of regular administration of insulin.

At the third coaching session, her vision and 3-month goal remained the same. Her short-term plans following the doctor's visit were to take her insulin as prescribed (for which she ranked both the importance and her confidence level as 9 out of 10, respectively), consume each of her five favourite vegetables at least once per day, avoid drinking sodas and read information concerning carbohydrate counting. She stated that she found it beneficial discussing her eating habits. The patient noted that her pillbox was critical in helping her remember to take her medications. Hence, she made a plan to put the insulin pen together with her pillbox, so that she can remember the injection when she takes her pills.

At the fourth session, she reported excitedly that she had been taking insulin consistently without missing a dose. She also reported moving around more and doing more house chores. She stated 'I can do it (house chores), insulin gave me strength to do it. It is bringing my sugar down to where I want.' She also reported cutting the quantity of frequently taken carbohydrates by half and increasing vegetable intake. She stated that having a food plan 'helped a whole lot'. She expressed more clarity on her newfound motivation for working to get her diabetes under control. She revised her vision statement to read 'I am saving my life! I do not want to die. I do want to live to at least 90. This is my way of trying to save my life so that I can be that old'. She retained this new vision for the rest of the intervention period. Her goal to bring down her HbA1c to 9\% in the shortterm remained the same, and she hoped to achieve this goal by her next doctor's visit. Her short-term plans were to replace her missing glucometer, continue taking insulin as prescribed, maintain the halving of carbohydrate portion sizes and double vegetable intake at supper. At the end of the session, she stated 'I have come a long way from our first conversation. I have learnt a lot from our session'.

At the fifth session, she was still taking insulin consistently. The approach of keeping her insulin pen along with the pillbox had worked well. She had an HbA1c test between coaching sessions 4 and 5 that showed a value of $10.8 \%$, down from the $13.9 \%$ recorded at the beginning of the intervention. This was not yet at her goal of $9 \%$ but was trending in the right direction. Further conversations were had on her dietary management goals and plans, and she decided to include a plan to purchase a blender for juicing vegetables in her updated short-term plans.

The sixth coaching session was eventful. The patient was crying on the phone and described her mood as 'feeling angry, bad and let down'. The patient stated that she was frustrated and disappointed at the outcome of a continuing care visit with her doctor the previous day. During this visit, the doctor changed her insulin dosing from a single dose of long-acting insulin at bedtime to four times daily, with the addition of a dose of rapidacting insulin before each meal. She did not feel that this change was necessary considering that her $\mathrm{HbA} 1 \mathrm{c}$ had dropped from $13.9 \%$ a few months earlier to $10.8 \%$ in the most recent test. She felt unheard and described the prescription as unfair. This frustration reflected in an updated DDS assessment after the visit, in which her score for the scale item 'Feeling that my doctor doesn't take my concerns seriously enough' went up two points.
The patient was worried about the new prescription because she stated that following a similar regimen in the past 'took away so much joy from her life'. Despite the progress she had made in the past few months, she said that she felt like 'quitting everything'. The coach listened mindfully and expressed empathy, acknowledgement and validation, gave the patient room to vent and helped her overcome the negative feelings. On review of goals and plans, the patient noted that she had purchased a blender for juicing as per her plan in session 5 but was yet to replace her glucometer. She rated both her confidence level and importance of taking the long-acting insulin at night as a 10 out of 10 . However, she ranked her confidence level at 5 for taking rapidacting insulin at meal times. At the end of the session, the patient expressed gratitude for the support.

By the seventh coaching session, the patient had ordered a replacement glucometer. She was still taking the once-daily longacting insulin as prescribed, but she often forgets the rapid-acting insulin during mealtimes and only takes it a few days in a week.

At the eighth and final coaching session, the patient noted that she had improved her rapid-acting insulin adherence to daily but often only once per day as compared with the recommended three, that is, one-third of the time. The session ended with her reaffirming commitment to achieving her vision statement. In the end, she expressed gratitude for the coaching experience, stating 'I learnt a lot... getting there, though slowly. At least better than what it used to be; from not taking insulin at all to taking two shots per day'.

\section{OUTCOME AND FOLLOW-UP \\ Timeline}

The timeline for the patient's journey through the intervention described in this case report is summarised in figure 1. The patient was enrolled in the intervention on 16 July 2018, completed coaching on 1 December 2018 and had a postintervention follow-up visit and assessment on 13 February 2019. Some of the key events during the process (as outlined above) are summarised in figure 1 .

\section{Changes in diabetes distress}

The primary goal of the intervention was to reduce diabetes distress through health coaching. At the time of enrollment, the patient had a moderate level of overall diabetes distress (DDS score of 2.53) that was driven by high levels of regimen distress (4.0) and emotional burden (3.2). These distress levels were observed to be slightly elevated at a follow-up assessment at the initiation of coaching (DDS score of 2.94, Regimen Distress of 4.4, Emotional Burden of 4.2). By the mid-point of the intervention, the patient's distress levels had come down significantly (DDS score of 1.76, Regimen Distress of 1.8, Emotional Burden of 1.4). The reduced distress levels were sustained at a postintervention assessment administered 2 months after completing the intervention (DDS score of 1.71, Regimen Distress of 2.6, Emotional Burden of 1.8). Figure 2 shows the trajectories of the patient's distress levels from enrollment to the postintervention assessment. Scores that are 2.0 and above are considered significant levels of distress. ${ }^{3}$

At baseline, the patient assigned the highest possible score (ie, 6 'a very serious problem') to three DDS items (table 1). These items were 'feeling that I am often failing with my diabetes routine', 'not feeling motivated to keep up my diabetes selfmanagement' and 'feeling that I will end up with serious longterm complications, no matter what I do'. At the postintervention assessment, she rated these items 4 ('somewhat serious problem'), 


\begin{tabular}{|c|c|c|c|c|c|}
\hline $\begin{array}{l}\text { Patient confides in the coach that } \\
\text { she had not filled her insulin } \\
\text { prescription in years and makes a } \\
\text { plan to schedule a visit with } \\
\text { provider to discuss insulin inertia. }\end{array}$ & $\begin{array}{l}\text { Patient meets with } \\
\text { provider and discusses } \\
\text { insulin anxieties, gets } \\
\text { education and resources } \\
\text { to overcome her fears. }\end{array}$ & $\begin{array}{l}\text { Patient restarts insulin } \\
\text { after four years of } \\
\text { receiving but not } \\
\text { filling prescriptions. }\end{array}$ & $\begin{array}{l}\text { Provider increases } \\
\text { insulin dose from once } \\
\text { daily (long-acting insulin) } \\
\text { to four times daily } \\
\text { (rapid-acting } 3 \text { times). }\end{array}$ & $\begin{array}{l}\text { Patient confides in coach about } \\
\text { frustration with increase in insulin } \\
\text { frequency and threatens to "quit it } \\
\text { all". Coach helps patient overcome } \\
\text { frustration and keep going. }\end{array}$ & $\begin{array}{l}\text { At the end of the intervention, } \\
\text { patient was still taking long- } \\
\text { acting insulin consistently and } \\
\text { improved adherence to rapid- } \\
\text { acting insulin. }\end{array}$ \\
\hline
\end{tabular}

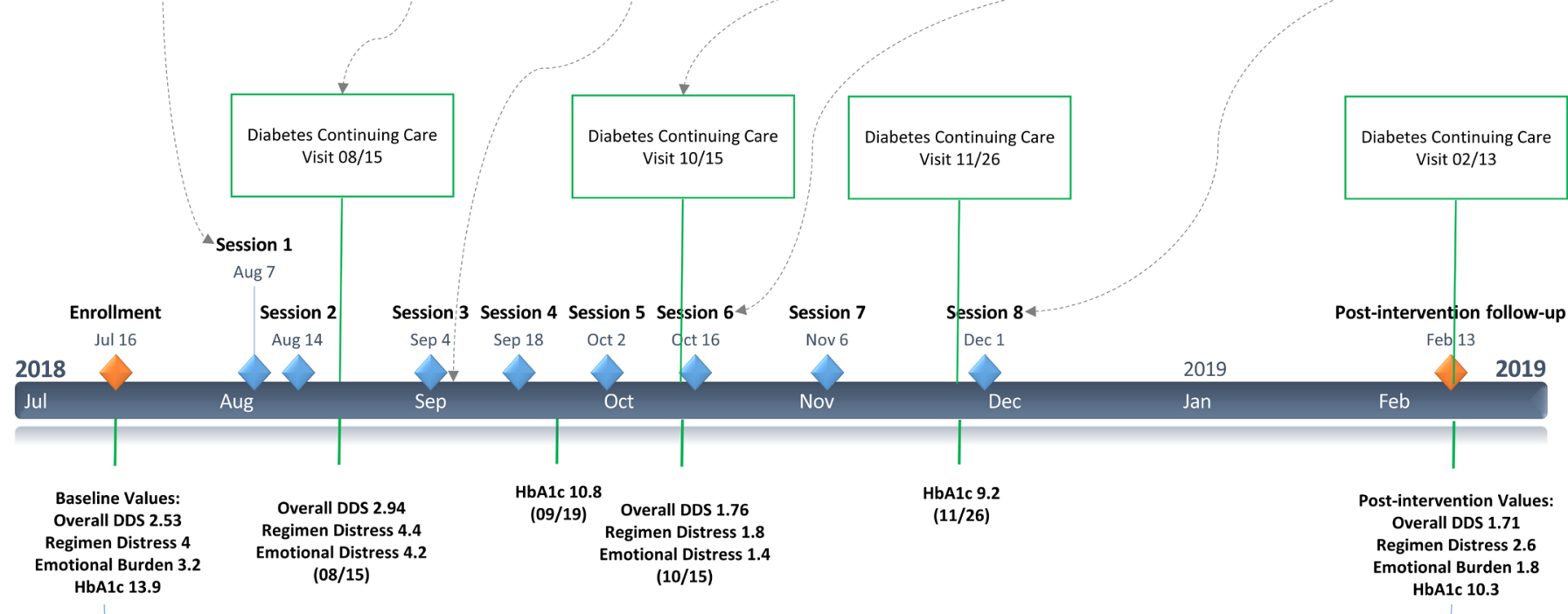

Significant reduction in diabetes distress and improvement

in glycemic control following the coaching intervention

Figure 1 Timeline. DDS, Diabetes Distress Scale; HbA1c, haemoglobinA1c.

3 (a moderate problem'), 1 (not a problem), respectively. These findings are not surprising considering that improving motivation and self-efficacy is at the heart of coaching. It is likely that the improvement in her adherence with insulin regimen due to the coaching intervention was a driving factor in reducing the ranking on the first item ('feeling that I am often failing with my diabetes routine'). At the baseline, the patient had practically resigned to fate and accepted that ending up with serious longterm complications was inevitable. This feeling of hopelessness disappeared after receiving coaching and she no longer felt that she would inevitably develop serious long-term complications. This is in line with her newly developed health vision to live to at least the age of 90 . Her feeling of lack of motivation to keep up with diabetes self-management also improved from 'a very serious problem' to 'a moderate problem'.

\section{Changes in glycaemic control}

As reflected in figure 3, the patient's glycaemic control improved during the intervention. Starting off with a very high HbA1c level (13.9\%), her 3-month coaching goal was to get to an HbA1c level of $9 \%$. She came close to achieving this goal, with an HbA1c level of $9.2 \%$ recorded during the fourth month of intervention. At the final assessment, two months after the

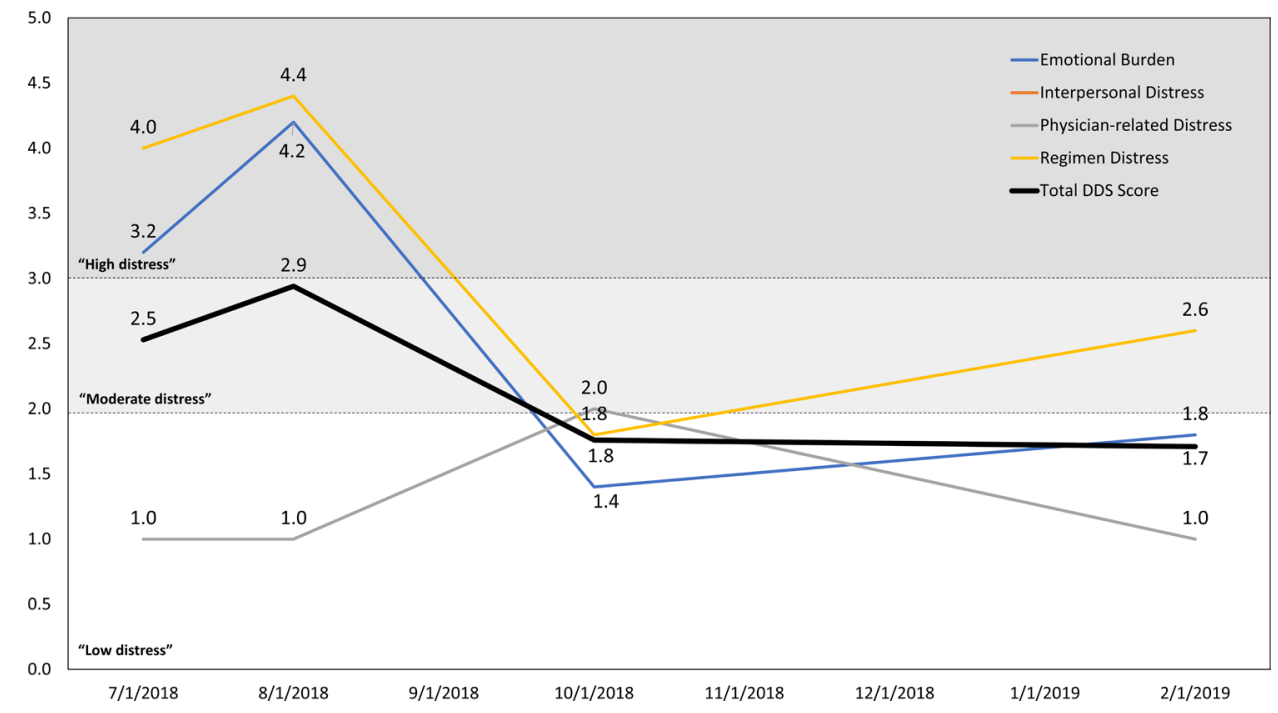

Figure 2 Patient's DDS trajectories during and after coaching. The scores for physician-related distress and interpersonal distress were identical at each time point, which is why the interpersonal distress line is not visible. DDS, Diabetes Distress Scale; HbA1c, haemoglobin A1c. 


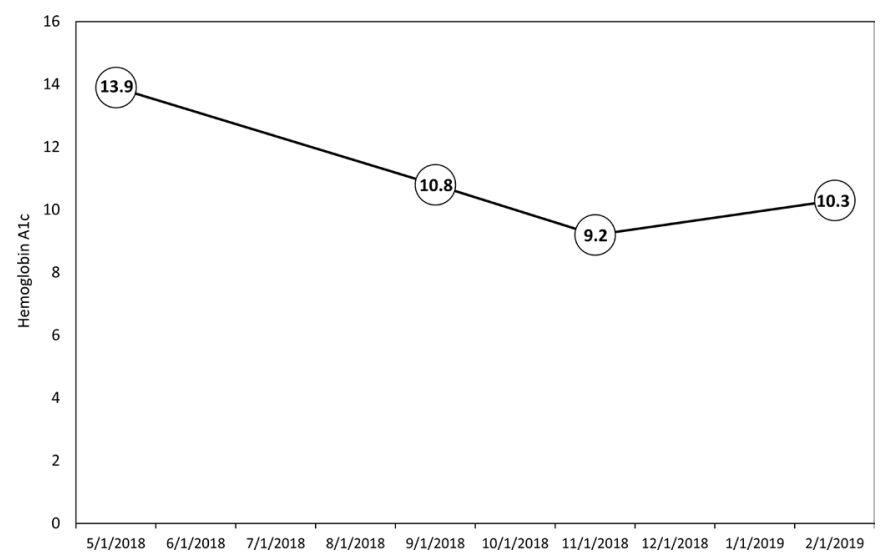

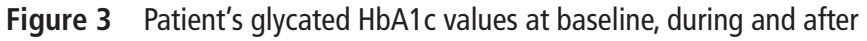
coaching. HbA1c, haemoglobin A1c

intervention, her HbA1c increased to $10.3 \%$ but was still a $26 \%$ relative reduction compared with the baseline value.

\section{Changes in self-management behaviours}

The most remarkable change in the patient's self-management behaviour during the coaching intervention was the change in her insulin adherence. She went from receiving and ignoring insulin prescriptions over a 4-year period to consistently taking longacting insulin daily and taking at least one-third of her rapidacting insulin dose daily. At goal reviews during her coaching sessions, she also reported improving her dietary behaviours, particularly, increasing fruit and vegetable consumption and halving carbohydrate intake, and increasing her physical activity levels, particularly, doing more house chores.

\section{GLOBAL HEALTH PROBLEM LIST}

- Diabetes distress, an indicator of poor emotional well-being, is a common and important barrier to self-management and control of diabetes.

- Patients do not often feel capable of fully expressing their needs and concerns with their doctor. In the case of this patient, she was unable to discuss her anxieties regarding insulin and hypoglycaemia, resulting in poor adherence to insulin for several years.

- Health coaching is well suited to addressing the underlying contributors and consequences of diabetes distress and improving patients' motivation and self-efficacy for diabetes self-management.

\section{GLOBAL HEALTH PROBLEM ANALYSIS}

Diabetes distress, an indicator of poor emotional well-being, is a common and important barrier to self-managing and controlling diabetes. Diabetes distress has a strong inverse association with positive diabetes self-management behaviours. ${ }^{6-10}$ Reductions in diabetes distress are associated with clinically significant reductions in HbA1c, ${ }^{11} 12$ and changes in glycaemic control and diabetes distress correspond with each other over time. ${ }^{7-9}$ Thus, controlling diabetes distress should be a routine component of comprehensive diabetes care. ${ }^{13}$

Often, patients do not feel capable of fully expressing their needs and concerns with their doctor. This results in poor adherence with treatment regimen and the attendant negative consequences, especially for ongoing chronic care management. In the case of this patient, she was unable to discuss her anxieties about insulin, resulting in poor adherence for about 4 years. It has been proposed that one of the ways that chronic care coaches add value to patient care is by bridging gaps between clinicians and their patients, ${ }^{14}$ and there is evidence that health coaching strengthens patients' relationship with and trust in their providers. ${ }^{15}$ This was certainly the case with this patient. Following interaction with the coach, the patient felt empowered to discuss her insulin concerns with the doctor. Opening up to the provider on her insulin fears provided the opportunity for her to receive education and reassurance that she can safely administer insulin at home without getting into hypoglycaemic coma.

Health coaching is well suited to addressing the underlying contributors and consequences of diabetes distress. Health coaching seeks to enlighten the recipient and facilitate health behaviour change in order to achieve health or wellness goals. Several behavioural change theories underlie health coaching, including the social cognitive theory and the transtheoretical model. ${ }^{16}$ In the context of this study, the authors' conceptualisation of health coaching aligns with the articulation in two previous reviews, ${ }^{17}{ }^{18}$ as reflected in the following definition:

A patient-centered approach wherein patients at least partially determine their goals, use self-discovery or active learning processes together with content education to work toward their goals, and self-monitor behaviors to increase accountability, all within the context of an interpersonal relationship with a coach. The coach is a healthcare professional trained in behavior change theory, motivational strategies, and communication techniques, which are used to assist patients to develop intrinsic motivation and obtain skills to create sustainable change for improved health and wellbeing. ${ }^{18}$

Interventions for alleviating diabetes distress need to help patients express their feelings about diabetes and improve their self-efficacy in meeting their diabetes care needs. ${ }^{19}$ By establishing trust and rapport, building a growth-promoting relationship and helping clients deal with negative emotions, health coaching can help patients express their feelings. ${ }^{20}$ Furthermore, coaching can help patients improve motivation and self-efficacy for diabetes self-management through the use of appreciative inquiry and motivational interviewing. ${ }^{20}$ These coaching techniques formed the basis for the intervention. There is growing evidence behind the various coaching techniques, particularly motivational interviewing ${ }^{21-24}$ — a collaborative and goaloriented style of communication that helps strengthen personal

\section{Learning points}

The Diabetes Distress Scale helps identify patients facing emotional barriers to diabetes self-management and it can be easily administered in primary care settings.

- Patients dealing with diabetes distress need to be supported to express their feelings about diabetes and improve selfefficacy in meeting their diabetes care needs.

- Health coaching provides patients with a safe nonjudgemental space to express their feelings, explore and address the underlying contributors and consequences of diabetes distress and improve their motivation and selfefficacy for diabetes self-management.

- Health coaches can help bridge gaps between clinicians and patients, helping avert poor adherence to treatment because of such gaps.

- Health coaches working remotely can be successfully integrated into primary care workflow. 
motivation for and commitment to a specific goal, in a nonjudgemental and empathetic atmosphere. ${ }^{25}$

Contributors CCC and JLS conceived and designed the study with contributions from BS. BS conducted the intervention. NA and CCC analysed and interpreted the data. CCC made the first draft of the manuscript and all authors revised it critically for important intellectual content. All authors approved the final version for publication and agree to be accountable for all aspects of the work.

Funding This study was supported by a grant from the Institute of Coaching, McLean Hospital, a Harvard Medical School Affiliate.

Competing interests None declared.

Patient consent for publication Obtained.

Provenance and peer review Not commissioned; externally peer reviewed.

ORCID iD

Charles C Chima http://orcid.org/0000-0002-5162-760X

\section{REFERENCES}

1 Snoek FJ, Bremmer MA, Hermanns N. Constructs of depression and distress in diabetes: time for an appraisal. Lancet Diabetes Endocrinol 2015;3:450-60.

2 Glasgow RE, Edwards LL, Whitesides $\mathrm{H}$, et al. Reach and effectiveness of DVD and in-person diabetes self-management education. Chronic IIIn 2009;5:243-9.

3 Fisher L, Hessler DM, Polonsky WH, et al. When is diabetes distress clinically meaningful?: establishing cut points for the diabetes distress scale. Diabetes Care 2012:35:259-64.

4 Fisher EB, Brownson CA, O'Toole ML, et al. Ecological approaches to selfmanagement: the case of diabetes. Am J Public Health 2005;95:1523-35.

5 Polonsky WH, Fisher L, Earles J, et al. Assessing psychosocial distress in diabetes: development of the diabetes distress scale. Diabetes Care 2005;28:626-31.

6 Joensen LE, Tapager I, Willaing I. Diabetes distress in Type 1 diabetes--a new measurement fit for purpose. Diabet Med 2013;30:1132-9.

7 Fisher L, Skaff MM, Mullan JT, et al. Clinical depression versus distress among patients with type 2 diabetes: not just a question of semantics. Diabetes Care 2007;30:542-8.

8 Fisher L, Mullan JT, Arean P, et al. Diabetes distress but not clinical depression or depressive symptoms is associated with glycemic control in both cross-sectional and longitudinal analyses. Diabetes Care 2010;33:23-8.
9 Aikens JE. Prospective associations between emotional distress and poor outcomes in type 2 diabetes. Diabetes Care 2012;35:2472-8.

10 Fisher L, Hessler D, Glasgow RE, et al. REDEEM: a pragmatic trial to reduce diabetes distress. Diabetes Care 2013:36:2551-8.

11 Zagarins SE, Allen NA, Garb JL, et al. Improvement in glycemic control following a diabetes education intervention is associated with change in diabetes distress but not change in depressive symptoms. J Behav Med 2012:35:299-304.

12 Strandberg RB, Graue M, Wentzel-Larsen T, et al. Relationships of diabetes-specific emotional distress, depression, anxiety, and overall well-being with $\mathrm{HbA1c}$ in adult persons with type 1 diabetes. J Psychosom Res 2014;77:174-9.

13 American Diabetes Association. Lifestyle management: standards of medical care in Diabetes-2018, 2018

14 Bennett HD, Coleman EA, Parry C, et al. Health coaching for patients with chronic illness. Fam Pract Manag 2010;17:24

15 Thom DH, Hessler D, Willard-Grace R, et al. Does health coaching change patients' trust in their primary care provider? Patient Educ Couns 2014;96:135-8.

16 Prochaska JO, Velicer WF. The transtheoretical model of health behavior change. Am J Health Promot 1997;12:38-48.

17 Olsen JM. Health coaching: a concept analysis. Nurs Forum 2014;49:18-29.

18 Wolever RQ, Simmons LA, Sforzo GA, et al. A systematic review of the literature on health and wellness coaching: defining a key behavioral intervention in healthcare. Glob Adv Health Med 2013:2:38-57.

19 Snouffer E. International diabetes Federation. 2016. diabetes distress: a real and normal part of diabetes. Available: https://www.idf.org/component/attachments/ attachments.html?id=589\&task=download

20 Moore M, Tschannen-Moran B, Jackson E. Coaching psychology manual. Philadelphia: Lippincott Williams \& Wilkins, 2015.

21 Butterworth SW, Linden A, McClay W. Health coaching as an intervention in health management programs. Dis Manage Health Outcomes 2007;15:299-307.

22 Linden A, Butterworth SW, Prochaska JO. Motivational interviewing-based health coaching as a chronic care intervention. J Eval Clin Pract 2010;16:166-74.

23 Burke BL, Arkowitz H, Menchola M. The efficacy of motivational interviewing: a metaanalysis of controlled clinical trials. J Consult Clin Psychol 2003;71:843-61.

24 Knight KM, McGowan L, Dickens C, et al. A systematic review of motivational interviewing in physical health care settings. Br J Health Psychol 2006;11:319-32.

25 Miller WR, Rollnick S. Motivational interviewing: helping people change. Guilford press, 2012.

Copyright 2021 BMJ Publishing Group. All rights reserved. For permission to reuse any of this content visit https://www.bmj.com/company/products-services/rights-and-licensing/permissions/ BMJ Case Report Fellows may re-use this article for personal use and teaching without any further permission.

Become a Fellow of BMJ Case Reports today and you can:

- Submit as many cases as you like

- Enjoy fast sympathetic peer review and rapid publication of accepted articles

- Access all the published articles

- Re-use any of the published material for personal use and teaching without further permission

Customer Service

If you have any further queries about your subscription, please contact our customer services team on +44 (0) 2071111105 or via email at support@bmj.com.

Visit casereports.bmj.com for more articles like this and to become a Fellow 